\title{
Development of an assay to assess genotoxicity by particulate matter extract
}

\author{
ALEXANDROS PRIFTIS $^{1}$, KONSTANTINOS PAPIKINOS ${ }^{1}$, MARINA KOUKOULANAKI ${ }^{1}$, \\ EFTHALIA KERASIOTI ${ }^{1}$, DIMITRIOS STAGOS ${ }^{1}$, KONSTANTINOS KONSTANTINOPOULOS ${ }^{2}$, \\ DEMETRIOS A. SPANDIDOS ${ }^{3}$, MARIANTHI KERMENIDOU ${ }^{4}$, SPYROS KARAKITSIOS ${ }^{4}$, \\ DIMOSTHENIS SARIGIANNIS ${ }^{4,5}$, ARISTIDES M. TSATSAKIS ${ }^{6}$ and DEMETRIOS KOURETAS ${ }^{1}$
}

\author{
${ }^{1}$ Department of Biochemistry and Biotechnology, University of Thessaly, Larissa 41221; ${ }^{2}$ Coffee Island S.A., \\ Patras 26334; ${ }^{3}$ Laboratory of Clinical Virology, University of Crete, Medical School, Heraklion 71409; \\ ${ }^{4}$ Aristotle University of Thessaloniki, Department of Chemical Engineering, Environmental Engineering Laboratory, \\ Thessaloniki 54124, Greece; ${ }^{5}$ Institute of Advanced Study (IUSS), Environmental Health Engineering, I-27100 Pavia, Italy; \\ ${ }^{6}$ Department of Forensic Sciences and Toxicology, Medical School, University of Crete, Heraklion 71003, Greece
}

Received November 14, 2016; Accepted January 30, 2017

DOI: $10.3892 / \mathrm{mmr} .2017 .6171$

\begin{abstract}
The current study describes a method for assessing the oxidative potential of common environmental stressors (ambient air particulate matter), using a plasmid relaxation assay where the extract caused single-strand breaks, easily visualised through electrophoresis. This assay utilises a miniscule amount $(11 \mu \mathrm{g})$ of particulate matter (PM) extract compared to other, cell-based methods $(\sim 3,000 \mu \mathrm{g})$. The negative impact of air pollution on human health has been extensively recognised. Among the air pollutants, PM plays an eminent role, as reflected in the broad scientific interest. PM toxicity highly depends on its composition (metals and organic compounds), which in turn has been linked to multiple health effects (such as cardiorespiratory diseases and cancer) through multiple toxicity mechanisms; the induction of oxidative stress is considered a major mechanism among these. In this study, the PM levels, oxidative potential, cytotoxicity and genotoxicity of PM in the region of Larissa, Greece were examined using the plasmid relaxation assay. Finally, coffee extracts from different varieties, derived from both green and roasted seeds, were examined for their ability to inhibit PM-induced DNA damage. These extracts also exerted an inhibitory effect on xanthine
\end{abstract}

Correspondence to: Professor Demetrios Kouretas, Department of Biochemistry and Biotechnology, University of Thessaly, Ploutonos 26 and Aiolou Street, Larissa 41221, Greece

E-mail: dkouret@uth.gr

Abbreviations: ROS, reactive oxygen species; TPC, total polyphenolic content; CGA, chlorogenic acid; PM, particulate matter; XO, xanthine oxidase; SOD, superoxide dismutase; CAT, catalase

Key words: coffee beans, roasting, polyphenols, particulate matter, genotoxicity, antioxidant activity oxidase and catalase, but had no effect against superoxide dismutase. Overall, this study highlights the importance of assays for assessing the oxidative potential of widespread environmental stressors (PM), as well as the antioxidant capacity of beverages and food items, with the highlight being the development of a plasmid relaxation assay to assess the genotoxicity caused by PM using only a miniscule amount.

\section{Introduction}

Aerobic organisms are exposed to reactive oxygen species (ROS). Free radicals are essential at low levels as they participate in various cellular processes, including signalling pathways and defence against pathogens $(1,2)$. ROS are mainly produced endogenously by mitochondria or during the 'oxidative burst' of macrophages, but they can also be produced by exogenous factors, such as environmental pollution, smoking and ionizing or ultraviolet radiation. Aerobic organisms possess a variety of antioxidant mechanisms to neutralise free radicals, including enzymes, as well as non-enzymatic compounds $(3,4)$. When in excess, free radicals may interact to damage cellular macromolecules, causing oxidative stress (5). This condition has been associated with various pathological conditions, such as cancer, diabetes and neurodegenerative diseases (6-8).

Over the past 30 years, particulate matter (PM) has emerged as a key pollutant, with well-known effects on human health. Only in 2012, there were approximately 3.7 million premature deaths related to air pollution (9). There are studies that demonstrate the implication of air pollutants in diseases of the cardiovascular system $(10,11)$, as well as of the respiratory system (12). There are even signs of genotoxicity, which ultimately can lead to lung cancer (13-15). Some of these adverse health effects have been associated to PM-induced oxidative stress (16). PM promotes ROS generation through two different mechanisms: i) the use of oxidative components adsorbed on the surface of the particles, resulting in oxidation; and ii) PM generates ROS mainly in pulmonary epithelial cells and macro- 
phages. However, fine and ultrafine particles have the ability to translocate into the systemic circulation and eventually, other organs and tissues may also be subjected to local inflammation associated with ROS generation $(10,17)$.

Since 2010, Greece faces a financial crisis with significant repercussion on per capita growth domestic product. This, in combination with the heavy taxation of oil used for heating (diesel) has resulted in the overwhelming use of biomass for domestic heating (18). Smaller PM fractions have been associated with biomass burning (19). The smaller PM fractions have a greater oxidative potential per unit mass, as they have the ability to adsorb more chemical substances, exhibiting a large surface area per mass (20). In addition, smaller particles are retained strongly by the lower respiratory system, a phenomenon that is more evident in children (21). Individual particle deposition across the three main regions of the respiratory tract depends on particle properties inter-individual physiology differences (22). Wood smoke particles are generally smaller than $1 \mu \mathrm{m}$ and consist of several toxic compounds such as PAHs, quinones and metals, that enhance the particle-induced health effects (23).

Most commonly, PM10 and PM2.5 are measured as indicators of air quality. Studies have shown that PM2.5 in particular can lead to serious health issues, due to the small aerodynamic diameter of these particles that allows them to reach the alveoli, through the induction of oxidative stress, inflammation and genotoxicity (24-27).

Based on the above, this study aimed to assess the oxidative stress induced by exposure to urban PM and the beneficial effect of consuming a highly antioxidant beverage, such as coffee. Towards this aim, the detailed population exposure to PM during wintertime, as well as the chemical composition and the chemically-induced oxidative stress were analysed. Following the chemical characterization of these samples, EA.hy926 cells were exposed at PM2.5 concentrations to assess the cytotoxicity of PM.

One main issue for the majority of PM-associated studies appears to be the small sample quantity of PM obtained through the filters of monitors, a possible prohibiting factor in the experimental design (28). Cell culture experiments require a substantial amount of extract in order to obtain the desired concentration each time in the flask. With the method described herein, the amount of used extract was reduced to a minimum. Moreover, the possible protective effect of food extracts, such as coffee, was examined.

Coffee is a very popular beverage due to its pleasant characteristics (taste and aroma). Its worldwide annual production exceeds $8 \mathrm{Mt}$, with an average daily consumption of 2.3 billion cups (29). As a beverage, coffee is rich in polyphenols and abundant in chlorogenic acid (CGA) (30). A number of studies have investigated the quantity and the beneficial effects of CGA (31-33) and the antioxidant properties of coffee beans (34).

\section{Materials and methods}

Field measurements. PM2.5 measurements were carried out from the 10th to 22nd of December 2015 at two different sampling sites in the urban area of Larissa, Greece, an urban background and a traffic site. PM2.5 particle fractions were collected using low volume air samplers (ENCO PM; TCR
Tecora, Milan, Italy) equipped with PM2.5 sampling heads that meet the EN 14907 standards operating at a flow-rate of $38 \mathrm{l} / \mathrm{min}$. Sampling duration was $24 \mathrm{~h}$. The inlet sampling points were at a height of $10 \mathrm{~m}$ from the ground. PM2.5 samples were collected on PTFE membrane filters with PMP supporting ring ( $\varnothing 47 \mathrm{~mm}$, pore size $2 \mu \mathrm{m}$; Pall Life Sciences, Port Washington, NY, USA), which are appropriate not only for gravimetric and chemical analysis of PM, but also for genotoxicity tests. Filters were weighed at least 3 times before and after the sampling on an electronic microbalance with a sensitivity of $\pm 1 \mu \mathrm{g}$ and were stored under controlled conditions of temperature $\left(20-23^{\circ} \mathrm{C}\right)$ and relative humidity (30-40\%).

Chemical analysis on PM filters. PM2.5 ambient concentrations were obtained and chemical analyses were conducted for black carbon content and the elemental composition of the particles. Black carbon concentration levels were estimated using a non-destructive analysis method developed by a Magee Scientific SootScan ${ }^{\mathrm{TM}}$ Model OT21 Optical Transmissometer. The elemental constituents of PM2.5, were determined on one half of each $47 \mathrm{~mm}$ Teflon filter by ED-XRF using an Epsilon 5 XRF instrument (PANalytical B.V., Eindhoven, The Netherlands). For the calibration of the instrument, $27-\mu \mathrm{m}$-thin standards were used. Corrections for instrument errors and the effect of the matrix on the X-ray emission intensities were also determined. Method detection limits were between 1 and $70 \mathrm{ng} / \mathrm{cm}^{2}$ for $\mathrm{Na}, \mathrm{Mg}, \mathrm{Al}, \mathrm{Si}, \mathrm{S}, \mathrm{Cl}, \mathrm{K}, \mathrm{Ca}, \mathrm{Ti}$, $\mathrm{V}, \mathrm{Mn}, \mathrm{Fe}, \mathrm{Ni}, \mathrm{Cu}, \mathrm{Zn}$ and $\mathrm{Pb}$. All samples were measured in duplicate according to standard operating procedures.

DTT assay. The oxidative potential of PM2.5 was estimated indirectly, on the basis of the rate of consumption of dithiothreitol (DTT) over time. The PM2.5 samples were stored at $-20^{\circ} \mathrm{C}$ in the dark prior to analysis. One fourth of a filter with a known mass of PM2.5 was added to a dark $4 \mathrm{ml}$ vial and labelled. Subsequently, $3 \mathrm{ml}$ of $100 \mu \mathrm{M}$ DTT in $0.1 \mathrm{M}$ phosphate buffer were added into the vial and the amount of DTT lost was measured (from 0 to $15 \mathrm{~min}$ ) at $37^{\circ} \mathrm{C}$. The vials were placed in a water bath and shaken. At indicated time points, an aliquot of $0.5 \mathrm{ml}$ of the reaction mixture was removed and added to $0.5 \mathrm{ml}$ of $10 \%$ TCA. TCA was used in order to terminte the reaction. When all time points were quenched, $50 \mu 1$ of $10 \mathrm{mM}$ DTNB (made in 0.1 M phosphate buffer, $\mathrm{pH}$ 7.4) were added forming 2-nitro-5-thiobenzoic acid (TNB). Subsequently, $2 \mathrm{ml}$ of $0.4 \mathrm{M}$ Tris-Base pH 8.9 with $20 \mathrm{mM}$ EDTA were added to chelate any transition metals. Light absorption was measured at $412 \mathrm{~nm}$, thus permitting us to quantify TNB, which has a molar absorptivity of $14,150 \mathrm{M}^{-1} \mathrm{~cm}^{-1}$. Linear regression was used between the measurement time points and the DTT loss in order to estimate the rate of DTT consumption. The results were expressed in terms of pmol DTT/min per PM mass $(\mu \mathrm{g})$ and volume $\left(\mathrm{m}^{3}\right)$ of air. As regards quality control samples, both method blanks and positive control were prepared and analysed at the same time as the unknown samples. Positive control samples contained all the reagents with $16.1 \mu \mathrm{l}$ of 9,10-phenanthrenequinone (PQN). Blank and positive control (or PQN) were run in triplicate.

PM extraction. The toxicity of ambient PM was determined according to the following procedure: PM2.5 samples on 
filters were kept at $-20^{\circ} \mathrm{C}$ in the dark prior to use. For sample measurement half of each PM-fraction filter (including the filter blank) was used for cellular toxicity and the other half for elemental analysis. The water-soluble components of PM were extracted from each filter half by ultrasonic agitation in $900 \mu \mathrm{l}$ distilled water at room temperature in the dark. The extraction was carried out overnight. The extracts were centrifuged at 3,409 $\mathrm{x} g$ for $1 \mathrm{~min}$. The supernatant was then filtered through a $0.22 \mu \mathrm{m}$ polypropylene filter into $1.5 \mathrm{ml}$ polypropylene microcentrifuge tubes. Method blanks were prepared using distilled water. Filter blanks were treated identically to the actual samples. The samples from different days were then pooled in a single sample of $1.65 \mu \mathrm{g} / \mu \mathrm{l}$.

Preparation of extracts from coffee beans. A total of 9 different coffee extracts were prepared. Seven came from the variety of Coffea arabica (Brazil and Decaf) and two from Coffea canephora (Robusta). For the first variety (Brazil), we had extracts of green beans and from 4 different roasting time points (R1:7 min; R2:6 min; R3:5 $\mathrm{min}$; R4:4 min) at $215^{\circ} \mathrm{C}$ so as to examine the effects of various roasting times on the activity.

For each sample, $10 \%$ w/v of ground (using mortar and pestle) coffee in double distilled water was prepared. Consequently, a 20 -min sonication step (70\% amplitude, $0.7 \mathrm{sec}$ cycle) and a 20 -min stirring under moderate heat $\left(35^{\circ} \mathrm{C}\right)$ were carried out. The extract was separated from solid residues by centrifuging each sample $\left(7,000 \mathrm{x} \mathrm{g}, 10 \mathrm{~min}, 25^{\circ} \mathrm{C}\right)$. Finally, each extract was aliquoted and kept at $-80^{\circ} \mathrm{C}$ for future use.

XTT cytotoxicity assay. The XTT assay kit (Trevigen, Gaithersburg, MD, USA) was used to assess cell viability. Briefly, EA.hy926 cells (kindly provided by Profesor Koukoulis, University of Thessaly, Larissa, Greece) were cultured in a 96-well plate in a $1 \times 10^{4}$ cells/well density in Dullbesco's modified Eagle's medium (DMEM) with $10 \%$ fetal bovine serum (FBS). After $24 \mathrm{~h}$, various concentrations of PM2.5 extract in serum-free DMEM were administered for $48 \mathrm{~h}$. Subsequently, in each well $50 \mu \mathrm{l}$ of XTT test solution were added. The test solution was prepared by mixing $50 \mu \mathrm{l}$ XTT labelling reagent with $1 \mu \mathrm{l}$ electron coupling reagent. Finally, after $4 \mathrm{~h}$ of incubation, the absorbance of each well was measured at 450 and $630 \mathrm{~nm}$ with the latter being a reference wavelength, in a BioTek ELx800 microplate reader (BioTek Instruments, Inc., Winooski, VT, USA). Serum-free DMEM was used as a negative control. Additionally, PM2.5 extract concentration alone in serum-free DMEM was tested at $450 \mathrm{~nm}$. The percentage of viability was calculated using the following formula: Viability $(\%)=\left[\left(\mathrm{OD}_{\text {control }}-\mathrm{OD}_{\text {sample }}\right) / \mathrm{OD}_{\text {control }}\right] \times 100$, where $\mathrm{OD}_{\text {control }}$ and $\mathrm{OD}_{\text {sample }}$ indicate the optical density of the negative control and the tested compounds, respectively.

Assessment of DNA strand cleavage. The plasmid (pBluescript-SK+, Fermentas, Waltham, MA, USA) DNA has a supercoiled conformation, but when a single-strand break occurs, it loses that conformation and adapts an open circular conformation. Based on this, the percentage of DNA strand cleavage, as well as the protective activity of food extracts was assessed. Firstly, $2 \mu \mathrm{l}(4 \mu \mathrm{g} / \mathrm{ml})$ of DNA was mixed with different volumes of sterilised PBS and PM2.5 sample. That way, a gradient of different concentrations of the PM2.5 samples was created. The final volume of the reaction was $10 \mu \mathrm{l}$. The samples were incubated for $45 \mathrm{~min}$ at $37^{\circ} \mathrm{C}$. Subsequently, $3 \mu 1$ of loading buffer (Bromophenol Blue $0.25 \%+30 \%$ Glycerol) was mixed to terminate the reaction and the samples were loaded on an $0,8 \%$ agarose gel. The samples were ran at $70 \mathrm{~V}$ for $55 \mathrm{~min}$. Ethidium bromide was used to stain the gel by suspending it in $12,5 \mu \mathrm{l}$ of ethidium bromide $(10 \mathrm{mg} / \mathrm{ml})$ and $250 \mathrm{ml}$ of distilled water for $30 \mathrm{~min}$. Consequently, the gel was washed with $250 \mathrm{ml}$ distilled water for $20 \mathrm{~min}$. Results were obtained by exposing the gels to UV and capturing a photo using MultiImage Light Cabinet (Alpha Innotech, San Leandro, CA, USA). Finally, we used the Alpha View suite to analyse the photos. When coffee extracts were introduced, the final reaction volume was increased to $13 \mu \mathrm{l}$.

Reducing power assay. The reducing power of the extracts was determined according to the protocol of Yen and Duh with some modifications (35). Briefly, each extract was dissolved in phosphate buffer $(0.2 \mathrm{M}, \mathrm{pH} 6.6)$ at various concentrations. A total of $250 \mu \mathrm{l}$ of the sample solution were added to $250 \mu \mathrm{l}$ of potassium ferricyanide $(1 \%)$ and incubated at $50^{\circ} \mathrm{C}$ for $20 \mathrm{~min}$, followed by cooling on ice for an additional $5 \mathrm{~min}$. Consequently, $500 \mu 1$ TCA (10\%) were added and the samples were centrifuged at $3,000 \mathrm{rpm}$ for $10 \mathrm{~min}$ at $25^{\circ} \mathrm{C}$. A total of $250 \mu \mathrm{l}$ from the supernatant were mixed with $250 \mu \mathrm{l}$ deionised water, as well as $50 \mu \mathrm{l}$ of ferric chloride $(0.1 \%)$. The samples were incubated at room temperature for $10 \mathrm{~min}$ and finally the absorbance was measured at $700 \mathrm{~nm}$. All experiments were carried out in triplicate and at least on two separate occasions.

Enzyme activity experiments. Polyphenolic compounds may absorb at the tested wavelengths, possibly increasing the optical density of the samples (even though, this was not the case for the currently tested extracts). Therefore, control samples were prepared identically to the test samples, without the extract. All initial reaction rates were in the linear scale and were measured during the first 2 to 4 min of the reaction depending on the enzyme. Each assay was performed in triplicate, and the optical density was measured using a Hitachi U-1900 spectrophotometer (Hitachi, Tokyo, Japan).

Assessment of xanthine oxidase (XO) activity. In order to determine XO activity and its inhibition, the production of uric acid from xanthine was used. The reaction mixture (with a final volume of $500 \mu \mathrm{l}$ ) comprised sodium phosphate buffer (33 mM, pH 7.5), xanthine $(4.8 \mu \mathrm{M})$, EDTA $(0.1 \mathrm{mM})$ and the coffee extract in various concentrations. Each reaction was initiated by the addition of XO (43 mU) and the absorbance was measured at $295 \mathrm{~nm}$ for $4 \mathrm{~min}$. The specific activity of each extract was measured by dividing the $\mathrm{IC}_{50}$ value (in $\mu \mathrm{g}$ of polyphenols) to the amount of polyphenols per $\mathrm{mg}$ of coffee. The $\mathrm{IC}_{50}$ value was determined as the extract's amount (in $\mu \mathrm{g}$ of polyphenols) that inhibited XO activity by $50 \%$, as monitored by the decrease in uric acid production.

Assessment of CAT activity. The activity of catalase was determined using the method described by Aebi (36). In this assay, changes in the absorbance of $\mathrm{H}_{2} \mathrm{O}_{2}$ as it becomes decomposed by CAT are measured, allowing the identification of potential inhibitors. Briefly, various coffee extract concentrations were 
added in $4 \mu \mathrm{l}$ of RBCL (diluted 1:40) in sodium potassium phosphate (67 mM, pH 7.4), followed by incubation at $37^{\circ} \mathrm{C}$ for 10 min. Consequently, $\mathrm{H}_{2} \mathrm{O}_{2}(0.6 \%)$ was added and the absorbance was measured at $240 \mathrm{~nm}$ for $2 \mathrm{~min}$. Specific activity was determined as in the case of XO.

Assessment of total superoxide dismutase (SOD) activity. SOD activity was determined using the method of Dieterich et al (37). In this method, pyrogallol autoxidation caused by superoxide anions present in the air can be inhibited by SOD. Therefore, a potential inhibitor will decrease the ability of SOD to protect pyrogallol. Briefly, the reaction mixture (final volume of $1 \mathrm{ml}$ ) included Tris- $\mathrm{HCl}(0.04 \mathrm{mM}, \mathrm{pH} 8.2)$, diethylenetriaminepentaacetic acid (DTPA, $0.08 \mathrm{mM}$ ), $30 \mu \mathrm{l}$ of RBCL (diluted 1:10) and various concentrations of the coffee extract. The mixture was incubated for $5 \mathrm{~min}$ at room temperature, followed by the initiation of the reaction by the addition of pyrogallol $(0.08 \mathrm{mM})$. The absorbance was measured at $420 \mathrm{~nm}$ for $3 \mathrm{~min}$. Control samples were prepared identically to the test samples without the extracts. Due to the fact that polyphenolic compounds are potential scavengers of superoxide anion, the possible inhibitory effect of coffee on pyrogallol autoxidation in the absence of SOD was examined (38).

Statistical analysis. Statistical analyses were carried out using SPSS software, version 20.0 (SPSS, Inc., Chicago, IL, USA). One-way ANOVA was applied, along with Dunnett's test for multiple pairwise comparisons. A value of $\mathrm{P}<0.05$ was considered to indicate a statistically significant difference.

\section{Results and Discussion}

For the XTT cytotoxicity assay, a number of different PM2.5 extract concentrations $(10,30,60$ and $80 \mu \mathrm{g}$ per $100 \mu \mathrm{l}$ well) were tested. Based on our results, PM2.5 ambient air concentrations ranged from 39 to $168 \mu \mathrm{g} / \mathrm{m}^{3}$, with an average of $105( \pm 46 \mathrm{SD}) \mu \mathrm{g} / \mathrm{m}^{3}$. At the same time, the observed DTT activity levels fall within the range of typical levels identified in other similar studies (20-180 $\mathrm{pmol} / \mathrm{min} / \mu \mathrm{g})(39)$. PM2.5 is highly chemically reactive as it can adsorb higher amounts of compounds, due to their higher active surface (21). This results in enhanced oxidative capacity, as well as higher inflammatory potential and pulmonary deposition. It has also to be noted that oxidative capacity has been associated with the metals content such as $\mathrm{Fe}$ and $\mathrm{Cu}(40)$.

As shown in Fig. 1, the PM extract caused a statistically significant decrease in cell viability from the $30 \mu \mathrm{g}$ concentration. Consequently, toxicity levels increased dose-dependently up to the maximum concentration used $(80 \mu \mathrm{g})$. However, this assay required a relatively large amount of the extract and therefore further analysis using cell cultures was not possible. Instead, in order to investigate the possible DNA-damaging potential of the PM extract, a plasmid relaxation assay was developed, based on the assay of Chang et al (41) with modifications, including the replacement of AAPH (a peroxyl radical-forming compound) with the PM extract.

The effects on the plasmid DNA are shown in Fig. 2. The gradient of PM2.5 concentrations caused a greater percentage of DNA to migrate to the upper zone of the gel that corresponds to the open conformation. Unfortunately, PM particles have

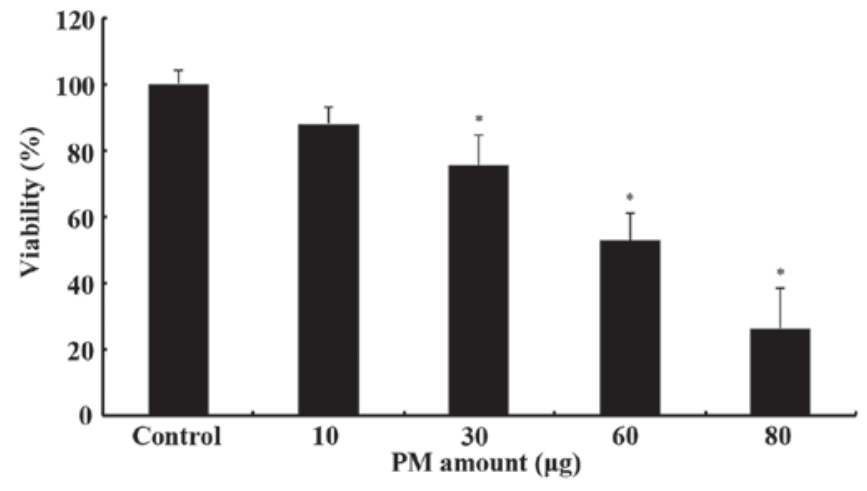

Figure 1. Cytotoxicity of particulate matter (PM) extract. Assessment of the PM extract on the viability of EA.hy 926 cells after $48 \mathrm{~h}$ of treatment. Cytotoxicity was estimated by XTT assay with the y-axis showing the percentage viability compared to the control and the $\mathrm{x}$-axis displaying the amount of PM in $\mu \mathrm{g}$ per $100 \mu 1$ well. Results are shown as the means \pm SEM. ${ }^{*} \mathrm{P}<0.01$, statistically significant differences compared to the control.

a quite complex composition and it is difficult to assign the observations strictly to only one of the components (13). It is also well-known that transition metals adsorbed onto PM can generate ROS through Fenton reactions (42). In fact, we did observe a good concentration of Fe in the composition analysis of our samples. Ferrous ions can generate $\mathrm{HO}^{\circ}$, which can subsequently cause DNA breaks by attacking the backbone and the bases. DNA is targeted by metal ions since it has an electron-rich structure, resulting thus in the formation of stable adducts (43).

Additionally, the presence of polycyclic aromatic hydrocarbons (PAHs) may also be responsible for the DNA damage. Studies have suggested that they can be metabolised from CYP450 enzymes and the products of this process can cause DNA damage as it is know from the literature $(44,45)$. Furthermore, the existence of environmental persistent-free radicals (EPFRs), such as semiquinones, on the surface of PM particles is seemingly of high importance for initiating the production of free radicals, particularly in cell-free conditions, such as our assay, particularly without the addition of $\mathrm{H}_{2} \mathrm{O}_{2}(46,47)$. EPFRs were initially found to be occurring upon chemisorption of an organic precursor to a redox metal site. This way the radical is stabilised and bound onto the surface of the particle (46). In the literature, it has been suggested that EPFRs are deprotonated in water and produce a superoxide anion which consequently is dismutated to $\mathrm{H}_{2} \mathrm{O}_{2}$, which can be used for the Fenton reactions with metals to produce the very reactive hydroxyl radical $(46,48-52)$.

However, despite the fact that the amount of at least $30 \mu \mathrm{g}$ of PM extract that the XTT method requires is relatively low, this corresponds to only $100 \mu \mathrm{l}$ of medium per well. The other cell-based methods would require $75 \mathrm{~cm}^{2}$ flasks, increasing the PM extract amount to at least 3,000 $\mu \mathrm{g}$ per $75 \mathrm{~cm}^{2}$ flask in order to assess its genotoxicity.

The amount of $11 \mu \mathrm{g}$ PM extract (in $13 \mu \mathrm{l}$ of the total volume) was selected as it causes significant DNA cleavage ( $\sim 70 \%$ cleavage, whilst remaining a small amount compared to the ones that the cell-based assays would require). When coffee extracts were introduced to the mixture of the reaction, a protective action on DNA was documented (Fig. 2B). In 

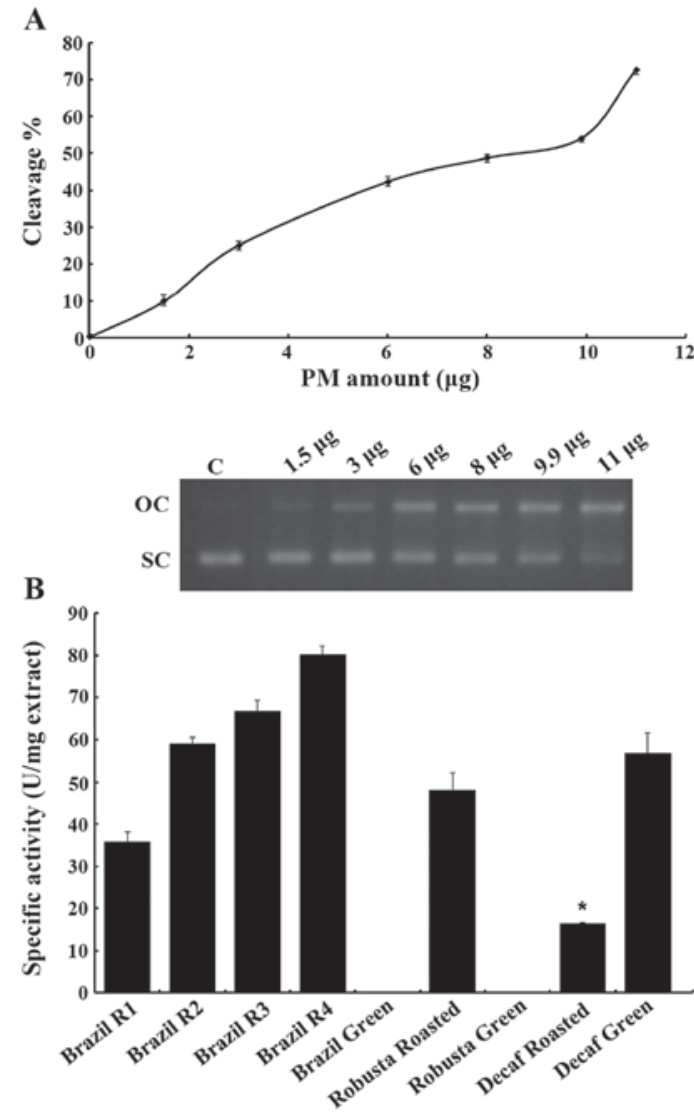

Figure 2. DNA cleavage from particulate matter (PM) extract and inhibition by coffee. (A) Effect of PM extract on DNA conformation. The diagram depicts the percentage of DNA cleaved per $\mu \mathrm{g}$ of the PM extract. All results are shown as the means \pm SEM. The electrophoresis displays the two conformations of the plasmid DNA, the supercoiled (SC) one and the open circular (OC) one, with the latter occurring after DNA cleavage. The control sample (C) is intact (SC conformation), while increasing amounts of PM extract ( $\mu \mathrm{g}$ per $10 \mu 1$ reaction) lead to DNA cleavage, increasing the intensity of the OC band. (B) The specific activity of each extract is shown, measured in units of activity per mg of coffee. A unit represents the amount of polyphenols required to prevent plasmid relaxation by $50 \%$. In the Brazil green and Robusta green samples, no inhibition was displayed. ${ }^{*} \mathrm{P}<0.01$, statistically significant difference between a roasted extract and its green counterpart. All results are shown as the means \pm SEM.

most occasions, coffee seems to protect DNA from breaking quite efficiently. Of course different extracts seem to achieve different degrees of protection, as is shown in Fig. 2B. Two out of three green bean coffee extracts (Brazil and Robusta) actually exhibited no DNA-protecting activity. This could be due to the fact that green beans are rich in small molecule antioxidants, which may act in a pro-oxidative manner when in excess (53), while during roasting novel antioxidant complexes are formed (e.g., melanoidins), which behave in a different manner. As previously demonstrated, during the roasting process, polyphenols can be incorporated into melanoidins (54). Only the decaffeinated green coffee extract showed the ability to protect DNA, while its roasted form was actually less powerful with the current assay. This could be due to the fact that the decaffeination process (Swiss Water process) may interact in some way with the antioxidants present in the beans. Interestingly enough, all of the green bean extracts actually failed to protect the DNA even in the absence of the PM2.5 extract. This is an intriguing result which could be further investigated as to why some of
Table I. Total polyphenolic content of the coffee extracts [adapted from Priftis et al, 2015 (34)].

Coffee extract

TPC (mg GAE/g coffee)

Brazil R1

$29.61 \pm 1.03$

Brazil R2

Brazil R3

Brazil R4

$35.26 \pm 2.01$

Brazil Green

$45.28 \pm 3.50$

Robusta Roasted

$42.55 \pm 4.05$

Robusta Green

$32.58 \pm 5.17$

$43.99 \pm 1.32$

Decaf Roasted

$52.71 \pm 3.11$

Decaf Green

$27.42 \pm 1.57$

$41.40 \pm 4.04$

these extracts cause DNA damage and why during the presence of a pollutant they may not. The extracts from Brazil as stated above were obtained from beans with different roasting times. The results demonstrated that the less the beans are roasted, the greater the protective effects become. The R4, R3 and R2 extracts actually were the most active ones among the tested extracts. Of note, the R1 extract, which was roasted for a longer time period than the others, ranked second to last. The activity of the roasted Decaf extract was observed to be at least 2-fold lower than that of the other extracts, thus ranking last out of the coffee extracts (apart from the green bean extracts).

Briefly, the ability of PM extract to induce DNA damage was exhibited using the aforementioned assay, as well as the potential protective effect following the addition of coffee extracts in the reaction mixture.

In addition, the antioxidant activity of these coffee extracts was assessed using the Reducing Power assay, as well as their potential inhibitory effect on XO. Furthermore, the extracts were tested for potential inhibitory activities against two antioxidant enzymes, namely catalase and SOD.

In the reducing power assay, the most potent extract was the Robusta green sample, as it displayed the highest specific activity (Fig. 3A). Specific activity is a unit that was previously developed in order to compare the activity of extracts, taking into consideration both the amount of polyphenols and their respective activity by dividing the amount of polyphenols required to reach the $\mathrm{IC}_{50}$ value to the amount of polyphenols contained per mg of ground coffee (34). The total polyphenolic content (TPC) of these coffee extracts has been previously determined and was also used in the current analysis. The TPC results are shown in Table I. A higher value of specific activity corresponds to a more potent extract. Therefore, the Robusta green extract displayed 22.52 units of specific activity, $35.2 \%$ higher than that of its roasted counterpart (16.66). In the decaffeinated variety, the green extract was more potent than the roasted one by $54.1 \%$ (11.56-7.5 units). In the third variety, Brazil, in which four different roasting degrees were examined, the green extract was the least active, having 84.7, 76.9, 41 and 18.8\% (8.5-15.7/15.04 $/ 11.99 / 10.1$ units) lower specific activity values compared with the roasted samples, with the most active being the less roasted one. It is noteworthy that the activity of the roasted extracts diminishes over roasting time, an observation that is frequent in the bibliography $(34,55,56)$. The reducing power assay allows 


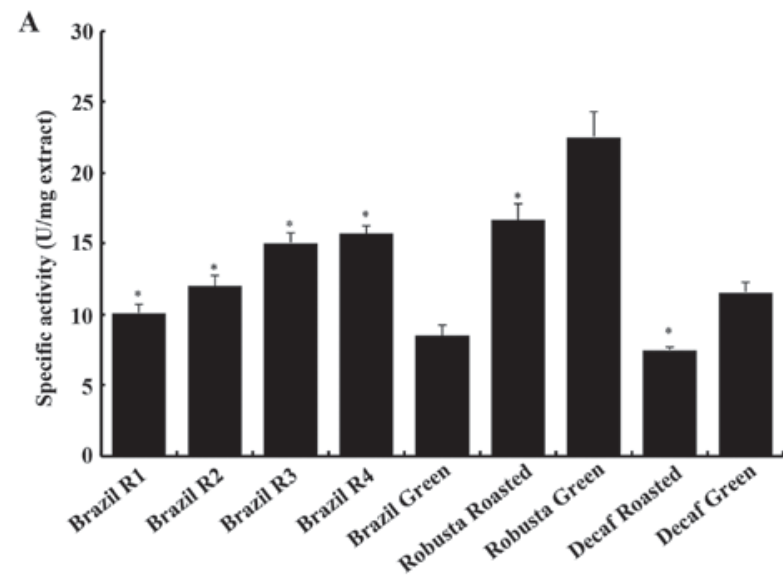

B

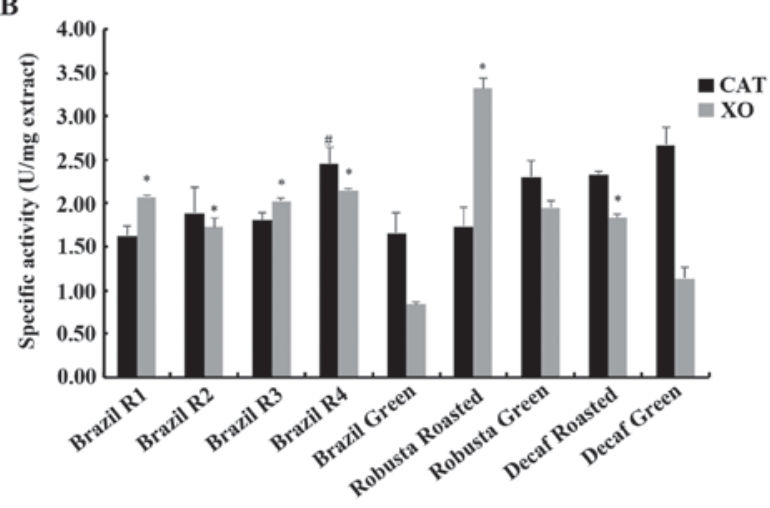

Figure 3. Antioxidant activity of coffee extracts by the Reducing power assay and inhibition of xanthine oxidase (XO) and catalase (CAT). (A) The specific activity of each extract is shown, measured in units of activity per mg of coffee. A unit represents the amount of polyphenols required to yield an absorbance of 0.5. All results are shown as mean \pm SEM. Statistically significant differences between roasted samples and their green counterparts at ( $\left(^{*}\right) \mathrm{P}<0.05$ level. (B) The specific activity is shown but in this case, a unit represents the amount of polyphenols required to inhibit the enzymatic activity by $50 \%$. The black bars represent the CAT assay while the grey ones the XO assay. All results are shown as the means \pm SEM. ${ }^{*} \mathrm{P}<0.05$ and ${ }^{\#} \mathrm{P}<0.05$, statistically significant differences between the roasted extracts and their respective green extracts for the XO assay and CAT assay, respectively.

the determination of the potency of a certain extract to reduce potassium ferricyanide $\left(\mathrm{Fe}^{3+}\right)$ to potassium ferrocyanide $\left(\mathrm{Fe}^{2+}\right)$ by offering an electron. Electron transfer is a major mechanism that mediates free radical neutralization and therefore, the results from the reducing power assay may provide information concerning the antioxidant activity of a tested extract.

Following the determination of their antioxidant capacity, the coffee extracts were examined as potential inhibitors of $\mathrm{XO}$, as shown in Fig. 3B. XO is a flavoprotein comprising two identical $145 \mathrm{kDa}$ subunits. It possesses four redox centers that are aligned in an almost linear fashion at the C-terminal 85-kDa molybdopterin-binding domain. The active form of $\mathrm{XO}$ is a $290 \mathrm{kDa}$ homodimer with each monomer being able to catalyse independently (57). XO is a cytosolic enzyme present in several mammalian tissues with the highest activity found in the liver and the intestine (58). However, $\mathrm{XO}$ can also be found extracellularly as it has an extremely high affinity for the endothelium (at the nanomollar scale) by binding to specific proteoglycans of the plasma membrane, potentially leading to further oxidative damage (59).
$\mathrm{XO}$ derives from xanthine dehydrogenase (XDH) and participates in purine degradation by metabolizing hypoxanthine to xanthine and further to urate. As a part of its mechanism of action, $\mathrm{XO}$ utilises molecular oxygen as the electron acceptor, thereby leading to superoxide radical and hydrogen peroxide production (60). However, it also leads to the production of uric acid, a strong antioxidant that accounts for $>50 \%$ of the antioxidant capacity of plasma (61). Consequently, this enzyme has an equivocal role in the redox status, since it produces both free radicals and uric acid. XO is a major contributor in free radical production during exercise due to the ischemia-reperfusion mechanism, but it has also been implicated in several diseases including myocardial infarction, hypertension, atherosclerosis, diabetes and cancer $(57,62)$. In addition, excessive uric acid production may lead to its crystallization and deposition in the joints, connective tissue and the kidneys, a condition known as gout and thus, XO inhibition may have therapeutic interest (63).

According to the results, all coffee extracts displayed inhibitory activity against XO, with the most potent inhibitor being the roasted Robusta sample, exhibiting 3.32 units of specific activity (corresponding to an $\mathrm{IC}_{50}$ value of $300 \mu \mathrm{g} / \mathrm{ml}$ ) and the least potent being the Brazil green extract with 0.84 units of specific activity, corresponding to an $\mathrm{IC}_{50}$ value of $1,193 \mu \mathrm{g} / \mathrm{ml}$. In the Brazil variety, the roasting process increased the inhibitory activity of coffee, as all four roasted samples had higher specific activity values. In more detail, the less roasted sample (R4) was the most potent inhibitor, exhibiting 2.15 units of specific activity $\left(\mathrm{IC}_{50}\right.$ at $465 \mu \mathrm{g} / \mathrm{ml}), \mathrm{R} 3$ had 2.03 units, R2 1.73 units and the more roasted sample (R1) displayed 2.07 units of specific activity. In the Robusta variety, the green extract was less potent than the roasted one, as it had 1.95 units of specific activity $\left(\mathrm{IC}_{50}\right.$ at $512.6 \mu \mathrm{g} / \mathrm{ml}$ ). As for the decaffeinated variety, again roasting boosted its inhibitory effect by increasing the specific activity from $1.14\left(\mathrm{IC}_{50}\right.$ at $\left.877.9 \mu \mathrm{g} / \mathrm{ml}\right)$ to $1.84\left(\mathrm{IC}_{50}\right.$ at $\left.544.2 \mu \mathrm{g} / \mathrm{ml}\right)$. Therefore, all coffee extracts resulted in $\mathrm{XO}$ inhibition and interestingly, roasting had an activating effect, increasing the inhibitory effect for each of the three tested coffee varieties.

The coffee extracts were also tested for their ability to inhibit SOD, which is an antioxidant enzyme. There are many SOD isoforms that all catalyse the reduction of superoxide anion to hydrogen peroxide. According to the results, no effect of either coffee sample was observed on SOD activity (data not shown). In vivo studies of coffee consumption in rats found either no effect or an increase on SOD activity $(64,65)$. Therefore, coffee may not affect the activity of this particular enzyme but could possibly alter its expression levels.

Finally, coffee extracts were tested for their ability to inhibit the activity of catalase (Fig. 3B). This enzyme catalyses the neutralization of hydrogen peroxide to oxygen and water. It is one of the fastest enzymes known to day and is considered one of the most important intracellular antioxidant mechanisms (66). All coffee extracts displayed an inhibition of catalase activity with the most potent being the $\mathrm{R} 4$ sample from the Brazil variety that had 2.45 units of specific activity $\left(\mathrm{IC}_{50}\right.$ at $408.1 \mu \mathrm{g} / \mathrm{ml}$ ). In all nine tested samples, the specific activity values ranged from 1.62-2.15 units (with the former having an $\mathrm{IC}_{50}$ value at $615.5 \mu \mathrm{g} / \mathrm{ml}$ ). In contrast to the $\mathrm{XO}$ activity assay, roasting did not affect the ability of coffee to interfere with catalase activity, apart from the R4 sample which displayed a significantly higher inhibitory effect compared to its green 
counterpart. In addition, caffeine depletion did not affect this assay. Furthermore, no differences were observed between the Coffea arabica and Coffea canephora varieties. The inhibition of catalase has been observed before by plant polyphenols as in the case of tea catechins (67). Despite the currently shown inhibitory effect, in in vivo studies coffee supplementation has been shown to improve the catalase system in rat liver (68). Therefore, further examination on the role of coffee on this enzyme is required.

The concomitant inhibition of both XO (a ROS-producing enzyme) and CAT (a ROS detoxifying enzyme) by coffee is an important finding, shedding light on its potential mechanism of action. It has been reported that CGA lactones, present in roasted coffee may inhibit XO (69). However, the effects of bioavailability and metabolism need to be taken into consideration, as coffee constituents ( $>1,000$ different compounds) need to be absorbed and pass through the liver before entering the bloodstream. CGAs, the main polyphenolic compound found in coffee exhibit high levels of bioavailability $(-30 \%)$ compared to other phenolics (70).

To conclude, PM displayed genotoxic activity as shown in the currently used plasmid relaxation assay. The advantage of this assay is the miniscule amount of PM extract required to obtain reliable results. This activity can be attributed to the transition metals and quinones that are present in the extract. The genotoxic activity of PM however, can be prevented through antioxidant mechanisms. In the current study, coffee extracts from three varieties (one Coffea canephora and two Coffea arabica of which one was decaffeinated) were examined. The roasted samples exhibited an inhibitory effect on the PM-induced plasmid relaxation as they had shown before in a AAPH-induced plasmid relaxation assay (34). The antioxidant activity of these coffee extracts was determined using the reducing power assay, as well as examining their effect on XO, SOD and catalase activity.

The current study deals with the evaluation of an assay based on plasmid relaxation for assessing the toxicity of ambient air PM and the antioxidant potential of a typical beverage such as coffee. Given the widespread exposure of the human population to ambient air particles of varying composition, aerodynamic characteristics and, consequently, toxicity it is important for the scientific community to have at bay integrated tools that can capture not only the toxic potency of the particles but also the protective potential of potential interventions such as the uptake of food additives. The joint evaluation of the antioxidant capacity of typically consumed food items, such as coffee against the oxidative potential of ubiquitous environmental stressors such as ambient air particulates could be an example in case of the new assay efficiency. This is of particular importance when dealing with population exposure in socioeconomically deprived areas, where environmental degradation is more evident, due to unsustainable environmental management or energy poverty. The results of this demonstrated that the plasmid relaxation assay developed herein manages to provide robust results on both oxidative stress and genotoxicity induced by exposure to typical ambient air fine particles found in cities. In addition, the assay allowed us to evaluate efficiently the antioxidant and thus protective potential of different coffee bean extracts. These results may be used as the basis for development of guidance regarding the type of coffee bean (both before and after toasting) that would provide the highest protection to population susceptible individuals exposed to PM with high genotoxic potency.

Based on our results, the plasmid relaxation assay developed and tested herein may prove to be a cost-effective manner for assessing the oxidative potential of environmental stressors, as well as for quantifying the antioxidant capacity and the protective action against the damage caused to DNA by food additives and other protective xenobiotics. The results obtained may be used to set the ground for the provision of guidelines promoting consumer behaviour that aims towards public health protection.

\section{References}

1. Schieber M and Chandel NS: ROS function in redox signaling and oxidative stress. Curr Biol 24: R453-R462, 2014.

2. Ray PD, Huang BW and Tsuji Y: Reactive oxygen species (ROS) homeostasis and redox regulation in cellular signaling. Cell Signal 24: 981-990, 2012.

3. Elias RJ, Kellerby SS and Decker EA: Antioxidant activity of proteins and peptides. Crit Rev Food Sci Nutr 48: 430-441, 2008.

4. Birben E, Sahiner UM, Sackesen C, Erzurum S and Kalayci O: Oxidative stress and antioxidant defense. World Allergy Organ J 5: 9-19, 2012.

5. Halliwell B: Free Radicals and Other Reactive Species in Disease. In: eLS. John Wiley \& Sons, Ltd., Chichester, UK, 2001.

6. Sosa V, Moliné T, Somoza R, Paciucci R, Kondoh H and LLeonart ME: Oxidative stress and cancer: An overview. Ageing Res Rev 12: 376-390, 2013.

7. Rochette L, Zeller M, Cottin Y and Vergely C: Diabetes, oxidative stress and therapeutic strategies. Biochim Biophys Acta 1840: 2709-2729, 2014.

8. Wang X, Wang W, Li L, Perry G, Lee HG and Zhu X: Oxidative stress and mitochondrial dysfunction in Alzheimer's disease. Biochim Biophys Acta 1842: 1240-1247, 2014.

9. World Health Organisation (WHO): Media centre. Ambient (outdoor) air quality and health. WHO, Geneva, pp1-7, 2014.

10. Brook RD, Rajagopalan S, Pope CA III, Brook JR, Bhatnagar A, Diez-Roux AV, Holguin F, Hong Y, Luepker RV, Mittleman MA, et al; American Heart Association Council on Epidemiology and Prevention, Council on the Kidney in Cardiovascular Disease, and Council on Nutrition, Physical Activity and Metabolism: Particulate matter air pollution and cardiovascular disease: An update to the scientific statement from the American Heart Association. Circulation 121: 2331-2378, 2010.

11. Franklin BA, Brook R and Arden Pope C III: Air pollution and cardiovascular disease. Curr Probl Cardiol 40: 207-238, 2015.

12. Arbex MA, Santos Ude P, Martins LC, Saldiva PHN, Pereira LAA and Braga ALF: Air pollution and the respiratory system. J Bras Pneumol 38: 643-655, 2012.

13. Borgie M, Ledoux F, Verdin A, Cazier F, Greige H, Shirali P, Courcot D and Dagher Z: Genotoxic and epigenotoxic effects of fine particulate matter from rural and urban sites in Lebanon on human bronchial epithelial cells. Environ Res 136: 352-362, 2015.

14. Billet S, Abbas I, Le Goff J, Verdin A, André V, Lafargue PE, Hachimi A, Cazier F, Sichel F, Shirali P, et al: Genotoxic potential of Polycyclic Aromatic Hydrocarbons-coated onto airborne Particulate Matter (PM 2.5) in human lung epithelial A549 cells. Cancer Lett 270: 144-155, 2008.

15. Golokhvast KS, Chernyshev VV, Chaika VV, Ugay SM, Zelinskaya EV, Tsatsak is AM, Karakitsios SP and Sarigiannis DA: Size-segregated emissions and metal content of vehicle-emitted particles as a function of mileage: Implications to population exposure. Environ Res 142: 479-485, 2015.

16. Chen LC and Lippmann M: Effects of metals within ambient air particulate matter (PM) on human health. Inhal Toxicol 21: 1-31, 2009.

17. Tanaka M, Takano H, Fujitani Y, Hirano S, Ichinose T, Shimada A and Inoue KI: Effects of exposure to nanoparticle-rich diesel exhaust on 8-OHdG synthesis in the mouse asthmatic lung. Exp Ther Med 6: 703-706, 2013. 
18. Sarigiannis DA, Karakitsios SP and Kermenidou MV: Health impact and monetary cost of exposure to particulate matter emitted from biomass burning in large cities. Sci Total Environ 524-525: 319-330, 2015.

19. Sarigiannis DA, Karakitsios SP, Kermenidou M, Nikolaki S, Zikopoulos D, Semelidis S, Papagiannakis A and Tzimou R: Total exposure to airborne particulate matter in cities: The effect of biomass combustion. Sci Total Environ 493: 795-805, 2014.

20. Sarigiannis D, Kyriakou S, Kermenidou M and Karakitsios S: The reactive oxidative potential from biomass emitted particulate matter (PM10, PM2.5 \& PM1) and its impact on human health. In: Proceedings of the 18th International Symposium on Environmental Pollution and its Impact on Life in the Mediterranean Region. Mediterranean Scientific Association of Environmental Protection, Crete, 2015.

21. Sarigiannis DA, Karakitsios SP, Zikopoulos D, Nikolaki S and Kermenidou M: Lung cancer risk from PAHs emitted from biomass combustion. Environ Res 137: 147-156, 2015.

22. Albuquerque-Silva I, Vecellio L, Durand M, Avet J, Le Pennec D, de Monte M, Montharu J, Diot P, Cottier M, Dubois F, et al: Particle deposition in a child respiratory tract model: In vivo regional deposition of fine and ultrafine aerosols in baboons. PLoS One 9: e95456, 2014

23. Kocbach Bølling A, Pagels J, Yttri KE, Barregard L, Sallsten G Schwarze PE and Boman C: Health effects of residential wood smoke particles: The importance of combustion conditions and physicochemical particle properties. Part Fibre Toxicol 6: 29 2009.

24. Cachon BF, Firmin S, Verdin A, Ayi-Fanou L, Billet S, Cazier F, Martin PJ, Aissi F, Courcot D, Sanni A, et al: Proinflammatory effects and oxidative stress within human bronchial epithelial cells exposed to atmospheric particulate matter (PM(2.5) and $\mathrm{PM}(>2.5)$ collected from Cotonou, Benin. Environ Pollut 185: 340-351, 2014

25. Lodovici $\mathrm{M}$ and Bigagli E: Oxidative stress and air pollution exposure. J Toxicol 2011: 487074, 2011.

26. Zakharenko AM, Engin AB, Chernyshev VV, Chaika VV, Ugay SM, Rezaee R, Karimi G, Drozd VA, Nikitina AV, Solomennik SF, et al: Basophil mediated pro-allergic inflammation in vehicle-emitted particles exposure. Environ Res 152: 308-314, 2017.

27. Golokhvast K, Vitkina T, Gvozdenko T, Kolosov V, Yankova V, Kondratieva E, Gorkavaya A, Nazarenko A, Chaika V, Romanova T, et al: Impact of Atmospheric Microparticles on the Development of Oxidative Stress in Healthy City/Industrial Seaport Residents. Oxid Med Cell Longev 2015: 412173, 2015.

28. Boisa N, Entwistle J and Dean JR: A new simple, low-cost approach for generation of the PM10 fraction from soil and related materials: Application to human health risk assessment. Anal Chim Acta 852: 97-104, 2014.

29. Higdon JV and Frei B: Coffee and health: A review of recent human research. Crit Rev Food Sci Nutr 46: 101-123, 2006.

30. Murthy PS and Naidu MM: Recovery of Phenolic Antioxidants and Functional Compounds from Coffee Industry By-Products. Food Bioprocess Technol 5: 897-903, 2012.

31. Sato Y, Itagaki S, Kurokawa T, Ogura J, Kobayashi M, Hirano T, Sugawara $\mathrm{M}$ and Iseki K: In vitro and in vivo antioxidant properties of chlorogenic acid and caffeic acid. Int J Pharm 403: 136-138, 2011

32. Xu JG, Hu QP and Liu Y: Antioxidant and DNA-protective activities of chlorogenic acid isomers. J Agric Food Chem 60 $11625-11630,2012$.

33. Henry-Vitrac C, Ibarra A, Roller M, Mérillon JM and Vitrac X: Contribution of chlorogenic acids to the inhibition of human hepatic glucose-6-phosphatase activity in vitro by Svetol, a standardized decaffeinated green coffee extract. J Agric Food Chem 58: 4141-4144, 2010

34. Priftis A, Stagos D, Konstantinopoulos K, Tsitsimpikou C, Spandidos DA, Tsatsakis AM, Tzatzarakis MN and Kouretas D: Comparison of antioxidant activity between green and roasted coffee beans using molecular methods. Mol Med Rep 12: 7293-7302, 2015

35. Yen GC and Duh DP: Scavenging Effect of Methanolic Extracts of Peanut Hulls on Free-Radical and Active-Oxygen Species. J Agric Food Chem 42: 629-632, 1994.

36. Aebi H: Catalase in vitro. Methods Enzymol 105: 121-126, 1984

37. Dieterich S, Bieligk U, Beulich K, Hasenfuss G and Prestle J: Gene expression of antioxidative enzymes in the human heart: Increased expression of catalase in the end-stage failing heart. Circulation 101: 33-39, 2000
38. Cos P, Ying L, Calomme M, Hu JP, Cimanga K, Van Poel B, Pieters L, Vlietinck AJ and Vanden Berghe D: Structure-activity relationship and classification of flavonoids as inhibitors of xanthine oxidase and superoxide scavengers. J Nat Prod 61: 71-76, 1998.

39. Velali E, Papachristou E, Pantazaki A, Choli-Papadopoulou T, Planou S, Kouras A, Manoli E, Besis A, Voutsa D and Samara C: Redox activity and in vitro bioactivity of the water-soluble fraction of urban particulate matter in relation to particle size and chemical composition. Environ Pollut 208 (Pt B): 774-786, 2016.

40. Terzano C, Di Stefano F, Conti V, Graziani E and Petroianni A: Air pollution ultrafine particles: Toxicity beyond the lung. Eur Rev Med Pharmacol Sci 14: 809-821, 2010.

41. Chang ST, Wu JH, Wang SY, Kang PL, Yang NS and Shyur LF: Antioxidant activity of extracts from Acacia confusa bark and heartwood. J Agric Food Chem 49: 3420-3424, 2001.

42. Valavanidis A, Vlahoyianni T and Fiotakis K: Comparative study of the formation of oxidative damage marker 8-hydroxy-2'-deoxyguanosine (8-OHdG) adduct from the nucleoside 2'-deoxyguanosine by transition metals and suspensions of particulate matter in relation to metal content and redox reactivity. Free Radic Res 39: 1071-1081, 2005.

43. Imlay JA, Chin SM and Linn S: Toxic DNA damage by hydrogen peroxide through the Fenton reaction in vivo and in vitro. Science 240: 640-642, 1988.

44. Longhin E, Pezzolato E, Mantecca P, Holme JA, Franzetti A, Camatini $\mathrm{M}$ and Gualtieri M: Season linked responses to fine and quasi-ultrafine Milan PM in cultured cells. Toxicol In Vitro 27: 551-559, 2013.

45. Delfino RJ, Staimer N, Tjoa T, Arhami M, Polidori A, Gillen DL, Kleinman MT, Schauer JJ and Sioutas C: Association of biomarkers of systemic inflammation with organic components and source tracers in quasi-ultrafine particles. Environ Health Perspect 118: 756-762, 2010.

46. Gehling W, Khachatryan L and Dellinger B: Hydroxyl radical generation from environmentally persistent free radicals (EPFRs) in PM2.5. Environ Sci Technol 48: 4266-4272, 2014

47. Farias MS, Pich CT, Kviecinski MR, Bucker NC, Felipe KB, Da Silva FO, Günther TM, Correia JF, Ríos D, Benites J, et al: Substituted 3-acyl-2-phenylamino-1,4-naphthoquinones intercalate into DNA and cause genotoxicity through the increased generation of reactive oxygen species culminating in cell death. Mol Med Rep 10: 405-410, 2014.

48. Dellinger B, Pryor WA, Cueto R, Squadrito GL, Hegde V and Deutsch WA: Role of free radicals in the toxicity of airborne fine particulate matter. Chem Res Toxicol 14: 1371-1377, 2001.

49. Squadrito GL, Cueto R, Dellinger B and Pryor WA: Quinoid redox cycling as a mechanism for sustained free radical generation by inhaled airborne particulate matter. Free Radic Biol Med 31: 1132-1138, 2001.

50. Alaghmand M and Blough NV: Source-dependent variation in hydroxyl radical production by airborne particulate matter. Environ Sci Technol 41: 2364-2370, 2007.

51. Valavanidis A, Fiotakis K, Bakeas E and Vlahogianni T: Electron paramagnetic resonance study of the generation of reactive oxygen species catalysed by transition metals and quinoid redox cycling by inhalable ambient particulate matter. Redox Rep 10: 37-51, 2005

52. Khachatryan L, Vejerano E, Lomnicki S and Dellinger B: Environmentally persistent free radicals (EPFRs). 1. Generation of reactive oxygen species in aqueous solutions. Environ Sci Technol 45: 8559-8566, 2011.

53. Bouayed J and Bohn T: Exogenous antioxidants - Double-edged swords in cellular redox state: Health beneficial effects at physiologic doses versus deleterious effects at high doses. Oxid Med Cell Longev 3: 228-237, 2010.

54. Perrone D, Farah A and Donangelo CM: Influence of coffee roasting on the incorporation of phenolic compounds into melanoidins and their relationship with antioxidant activity of the brew. J Agric Food Chem 60: 4265-4275, 2012.

55. Smrke S, Opitz SEW, Vovk I and Yeretzian C: How does roasting affect the antioxidants of a coffee brew? Exploring the antioxidant capacity of coffee via on-line antioxidant assays coupled with size exclusion chromatography. Food Funct 4: 1082-1092, 2013.

56. Bakuradze T, Lang R, Hofmann T, Stiebitz H, Bytof G, Lantz I, Baum M, Eisenbrand G and Janzowski C: Antioxidant effectiveness of coffee extracts and selected constituents in cell-free systems and human colon cell lines. Mol Nutr Food Res 54: $1734-1743,2010$ 
57. Borges F, Fernandes E and Roleira F: Progress towards the discovery of xanthine oxidase inhibitors. Curr Med Chem 9: 195-217, 2002

58. Krenitsky TA, Spector T and Hall WW: Xanthine oxidase from human liver: Purification and characterization. Arch Biochem Biophys 247: 108-119, 1986.

59. Houston M, Estevez A, Chumley P, Aslan M, Marklund S, Parks DA and Freeman BA: Binding of xanthine oxidase to vascular endothelium. Kinetic characterization and oxidative impairment of nitric oxide-dependent signaling. J Biol Chem 274: 4985-4994, 1999.

60. Choi EY, Stockert AL, Leimkühler S and Hille R: Studies on the mechanism of action of xanthine oxidase. J Inorg Biochem 98: 841-848, 2004

61. de Oliveira EP and Burini RC: High plasma uric acid concentration: Causes and consequences. Diabetol Metab Syndr 4: 12 , 2012.

62. Gomez-Cabrera MC, Borrás C, Pallardó FV, Sastre J, Ji LL and Viña J: Decreasing xanthine oxidase-mediated oxidative stress prevents useful cellular adaptations to exercise in rats. $J$ Physiol 567: 113-120, 2005.

63. Day RO, Kamel B, Kannangara DRW, Williams KM and Graham GG: Xanthine oxidoreductase and its inhibitors: Relevance for gout. Clin Sci (Lond) 130: 2167-2180, 2016.
64. Viana ALM, Fonseca M, Meireles EL, Duarte SM, Rodrigues MR and Paula FB: Effects of the consumption of caffeinated and decaffeinated instant coffee beverages on oxidative stress induced by strenuous exercise in rats. Plant Foods Hum Nutr 67: 82-87, 2012.

65. Abreu RV, Silva-Oliveira EM, Moraes MFD, Pereira GS and Moraes-Santos T: Chronic coffee and caffeine ingestion effects on the cognitive function and antioxidant system of rat brains. Pharmacol Biochem Behav 99: 659-664, 2011.

66. Pisoschi AM and Pop A: The role of antioxidants in the chemistry of oxidative stress: A review. Eur J Med Chem 97: 55-74, 2015.

67. Pal S, Dey SK and Saha C: Inhibition of catalase by tea catechins in free and cellular state: a biophysical approach. PLoS One 9: e102460, 2014

68. de Magalhães CS, Takarada JE, Carvalho NC, do Carvalho DC, de Andrade FL, Ferreira EB, Luccas PO and Azevedo L: The Coffee Protective Effect on Catalase System in the Preneoplastic Induced Rat Liver. J Chem 2016: 8570321, 2016.

69. Honda S, Miura Y, Masuda A and Masuda T: Identification of crypto- and neochlorogenic lactones as potent xanthine oxidase inhibitors in roasted coffee beans. Biosci Biotechnol Biochem 78: 2110-2116, 2014

70. Farah A, Monteiro M, Donangelo CMLS and Lafay S: Chlorogenic acids from green coffee extract are highly bioavailable in humans. J Nutr 138: 2309-2315, 2008. 